\title{
Study on the Intention of Personalized Group Travel
}

\author{
Chuting Liu \\ School of Management \\ University of Electronic Science and Technology of China \\ Zhongshan Institute (UESTC) \\ Zhongshan, China
}

Xinhong Xie

School of Management

University of Electronic Science and Technology of China

Zhongshan Institute (UESTC)

Zhongshan, China

\author{
Bingxia Guo \\ School of Management \\ University of Electronic Science and Technology of China \\ Zhongshan Institute (UESTC) \\ Zhongshan, China \\ Delphine Ya-Chu Chan \\ School of Management \\ University of Electronic Science and Technology of China \\ Zhongshan Institute (UESTC) \\ Zhongshan, China
}

\begin{abstract}
With the rapid development of "single economy" in China, and the continuous expansion of customized tourism market, this study explores the impact of personalized services, group services, tourism safety, and tourists' word-of-mouth on consumers' personalized group tourism willingness from the perspective of personalized group tourism. In this study, 447 questionnaires were collected, 40 invalid questionnaires and 407 effective samples were deducted, and the effective sample rate was $91 \%$. The results show that personalized service, tourists' word-of-mouth, group service and tourism safety have significant positive effects on the personalized group intention; especially, personalized service has the greatest impact on the personalized group intention, while tourism safety has only a slight significant impact on the personalized group intention.
\end{abstract}

Keywords-personalized service; groups service; tourist wordof-mouth; travel safe; personalized group intention

\section{INTRODUCTION}

According to iResearch consulting report, in 2017, the transaction scale of China's personalized tourism market was 6.8 billion yuan. In the future, with the enhancement of personalized tourism consumption awareness and the maturity of industry standard system, its market space is very broad. As one of the main body of tourism consumption, the post-90s especially have a special interest in personalized and customized leisure products. Traditional sightseeing activities have been unable to meet their consumption needs, and experiencing local life has gradually become the tourism target of most post-90s. In terms of travel group combination, the post-90s' preferences are also quite different from those of other age groups. They prefer to travel with friends in groups. The proportion of this type of travel group combination is as high as $71 \%$. Group travel with like-minded small partners has become a trend. In recent years, more and more post-90s choose to make friends through Internet channels and work out personalized tourism routes together, which have also caused a wave of personalized tourism [1]. The purpose of this study is to explore the individual willingness to join a group, and to study the impact changes among "personalized service", "join a group service", "tourists' word-of-mouth" and "tourism safety". Aiming at the rise of group consumption in various markets in China, college students are the main survey objects, and personalized group travel intention (PGI) research is carried out.

\section{LITERATURE REVIEW}

\section{A. Personalized Service}

Personalized service (PS) is a service provided to meet the personalized needs of consumers, increase the goodwill and trust of consumers, so as to attract more potential consumers. It includes: Line personalization, personalized proposition reflected by service, personalized matching of members of the group.

Wan Xiaoxue, Wang Yichen, Guo Shili, Zuo Jincheng, Wang Lei pointed out that on the basis of understanding customers' various interests and preferences, enterprises can meet customers' various needs and provide targeted special services to customers, which will make customers have a sense of trust in products or services, enhance their liking, and obtain good economic benefits [2]. Li Ruirui proposed that modern tourists seek diversified comprehensive satisfaction, have more and more interest in personalized tourism, have more sense of participation, and have diversified consumption levels and so on [3]. Qin Yue, Wang Kai, Zhang Xin, Liu Yingzhong according to the survey, the more willing the "empty nest youth" group is to purchase goods and services that meet their own personalized needs from the corresponding businesses through the network platform, and willing to pay a certain fee for their own personalized needs to meet their personalized needs [4].

Nowadays, personalized service has become the inevitable way of differentiated competition for major enterprises, and consumers' willingness to consume is closely related to the 
provided. Therefore,

high-quality personalized service hypothesis 1 is proposed in this study:

\section{H1: PS has a positive effect on PGI.}

\section{B. Group Service}

Group service (GS) provides diversified services for tourists who do not want to travel alone. It includes: the accuracy of group information, the provision of various booking services, the understanding of like-minded tourists, the provision of 24-hour customer service, the convenience of communication with group members, the high cost-effective recommendation of tourist routes, the understanding of each user's specific needs, the proper solution of customer service problems, the provision of tourist routes in line with the value proposition of passengers.

$\mathrm{He} \mathrm{Bi}$ points out that "group tour" is a tourism product different from other "group eating" and "group buying". It will be limited by many factors such as time, region, etc., and there are many uncertainties [5]. Yang Haidong believes that "group tour" in tourism industry means that travel agencies can group together with other travel agencies on the premise that the promised service contents and standards remain unchanged. This way, the clustering rate is high. Customers have more choices, travel agencies make the best use of resources, and travel time of tourists is more flexible. This win-win result makes "group" a travel mode that people are willing to accept [6]. The research of Yi Xinrui and Yao Guizhao shows that the group service of travel agencies mainly includes tour guide service, travel service and integration of resources to provide convenience for consumers. But with the development and progress of society, the traditional group tour can't meet the normalized needs of consumers. Compared with the uniform single group tour, personalized tourism is more personalized and can meet the special needs of tourists. It has strong flexibility, which makes personalized tourism the best choice for tourists in recent two years [7].

According to Lu Hanglan's research, more than $90 \%$ of the travelers have the willingness to make friends during the trip, however, about $50 \%$ of travelers feel that whether their social interaction needs are met during the journey is average or not . Qin Yue, Wang Kai, Zhang Xin andLiu Ying's research shows that desire for social interaction, lack of emotional sustenance and sense of security are still common problems of most "empty nest youth", so as to realize the organic combination of consumption and social contact [4]. Therefore, hypothesis 2 is proposed in this study:

\section{H2: GS will positively affect PGI.}

\section{Tourist Word-of-Mouth}

Tourist word-of-mouth (TWOM) is tourists' experience sharing after tour, and the evaluation of tourist products \& services. Tourists' word-of-mouth shows in the items whether the tourism evaluation shared by tourists has an impact on your travel intention.

Scholar Armdt J defines word-of-mouth communication as the verbal communication about a product, brand or service between the communicator and the recipient, and it is non- commercial oral communication [9]. The research of scholar Westbrook $r$ A. shows that consumer word-of-mouth communication is based on his consumption experience. After using a specific product, brand or service, the behavioral process of conveying his subjective evaluation of the product, brand or service to other consumers often uses informal channels to convey [10]. Research of scholars Herr, Paul, Frank Kardes and John Kim divide word-of-mouth into positive word-of-mouth and negative word-of-mouth. Among them, positive word of mouth refers to consumers' attitude towards the product, brand or service, and the positive evaluation of their products, brands or services [11].

Research of Wu Chuanbiao and Wan Shaojuan have found that in recent years, tourism market competition is increasingly in-depth, and tourism destination managers pay more and more attention to the improvement of the quality of tourists' experience and the shaping of post tour reputation [12]. The research of Yi Xinrui and Yao Guizhao points out that it is easy to form a good reputation among the masses of consumers by transforming users from users to fans, coupled with the rapid and wide spread of social platforms, so as to further integrate products into everyone's life [7]. Therefore, hypothesis 3 is proposed in this study

\section{H3: TWOM will positively affect PGI}

\section{Travel Safety}

Travel safety (TS) is the personal safety in the course of passenger travel and property security and personal information security at the time of payment. Song Haoyuan and others define tourism security as the basic condition for the normal operation of the tourism industry. The security needs of tourists come from the hidden dangers of information security in the existing online tourism market and personal and property security during tourism. The hidden dangers of personal and property security exist in the process of tourists' tourism, such as publishing false tourist evaluation and false discount for tourism product marketing [13].

Zhuang Zehui, Yuan Mingxia, Fan Weisheng and Zheng Guokai think that there is a problem of property payment in tourism. Because of the many links involved, the relatively unclear responsibilities, and the failure to form a unified industry standard, many consumers are hard to protect their rights and interests when purchasing tourism and products through online tourism websites. At the same time, consumer tourism security also includes personal privacy, travel, property and other security issues [14]. Research of Yang Qinqin and Xie Chaowu points out that safety demand is the basic demand for tourists to travel, and it is difficult for tourist destinations without safety guarantee to obtain the basis for sustainable growth [15].

At present, there are relatively few empirical researches on consumer tourism security, especially on the tourism security under the personalized group. Based on the relevant experience at home and abroad, this paper makes an investigation and Analysis on it, and probes into the future trend and new mode, and puts forward the hypothesis 4 :

\section{H4: TS will have a positive effect on PGI}


Based on the empirical research of the above scholars, the tourism industry is growing day by day, combined with the characteristics of young groups: social interaction needs, high acceptability to new things, the pursuit of consumption freedom and consumption experience to meet their personalized needs, the innovation of the traditional tourism business model, the development of new economic tourism products, and the enrichment of future tourism products and services. In this paper, the four single factors of personalized service, group service, tourist word-of-mouth and tourism security are integrated with the research model of personalized group intention, the established research model is shown in "Fig. 1".

\section{RESEARCH METHODS}

The research subject of this paper is the intention of individual tourism groups. The research methods mainly adopt the methods of literature collection and questionnaire survey. The research scope is Guangdong Province, and the research object is the people who have tourism plans in the future. The sampling method is convenient sampling. The questionnaire is distributed on the wechat social platform, and the respondents are asked to fill in the questionnaire in the form of forwarding links. Therefore, the respondents are basically in the place all the cities of Guangdong belong to. Most of the questionnaires are based on Likert five point scale method and NPs scale, with reference to the relevant literature of group tourism, and are finally modified and improved in combination with this study, including 3 questions of personalized service [16], [17], 9 questions of group service [16][18], 3 questions of tourism safety [19], and 1 question of tourist word-of-mouth [17]. According to the results of reliability analysis of 39 samples in the pretest, Cronbach's Alpha value of all variables was greater than 0.7, and formal questionnaire was issued after confirming the reliability. In this study, a total of 447 formal questionnaires were collected. After eliminating invalid data, the percentage of effective questionnaires was $91 \%$. Most of the respondents were 261 college students, of which the proportion of men and women were $35.14 \%$ and $64.86 \%$ respectively.

\section{DATA ANALYSIS}

\section{A. Reliability and Validity}

According to "Table I", reliability and validity analysis results show that Cronbach's alpha $>0.7$, item total correlation $>0.5, \mathrm{kmo}>0.5$, factor loading $>0.7$, composite reliability $(\mathrm{CR})>0.8$, ave $>0.5$ for personalized services (PS), tourism security (TS), group services (GS), and personalized group willingness (PGI). The factor load of the four variables is between 0.779 and 0.979 , which meets the standard of the standardization coefficient between 0.50 and 0.95 . Because CR value is more than 0.80 and AVE value is more than 0.50 , the reliability is high. It indicates that each variable has high internal consistency and good convergence validity.

According to the correlation analysis results in "Table II", Pearson's correlation coefficient and significance level indicate the correlation degree among all aspects in this study. Although correlation analysis can't prove the causal relationship between variables, it can see the close degree of correlation between variables. The values of personalized service (PS), tourism security (TS), group service (GS) and personalized group intention (PGI) are all between $0.122-0.400$, and the variables have low and medium correlation, respectively, and all show significant positive correlation. It shows that the more perfect the personalized service (PS) and the group service (GS) are, the more secure the tourism security (TS) is, and the higher the consumers' personalized group intention (PGI) is.

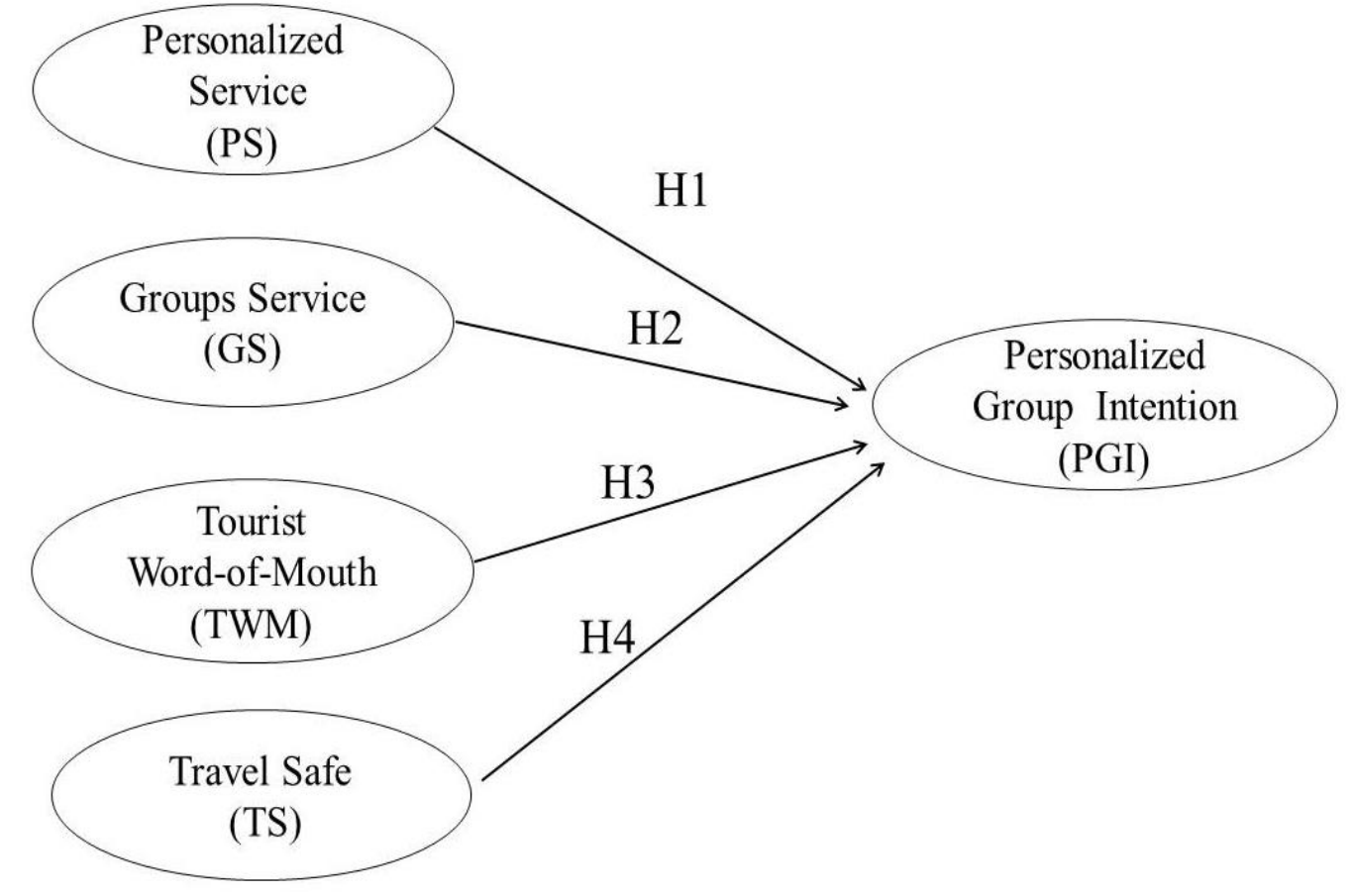

Fig. 1. Research framework. 
TABLE I. RELIABILITY AND VALIDITY

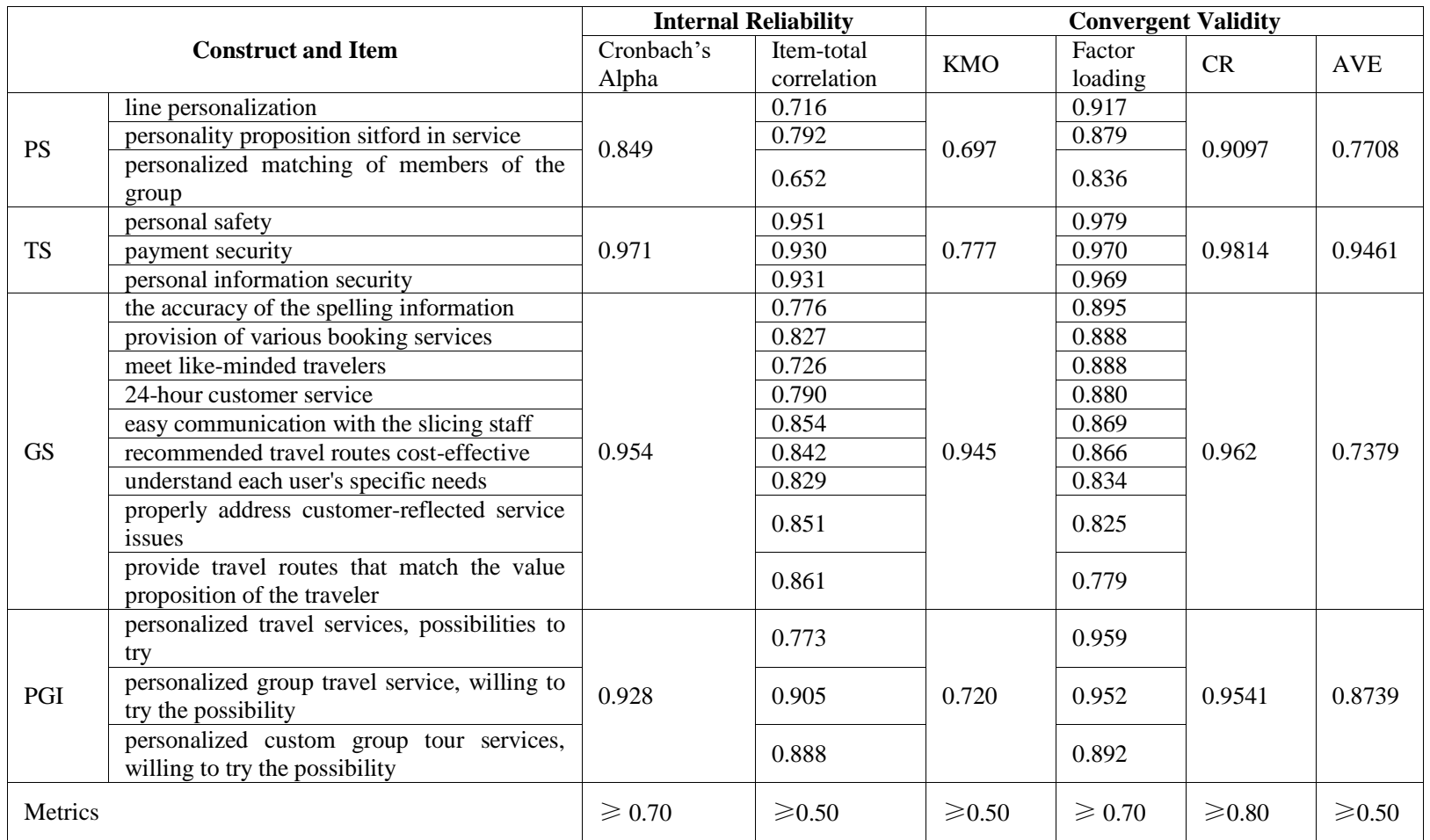

TABLE II. DISCRIMINANT VALIDITY

\begin{tabular}{|c|c|c|c|c|}
\hline Variable & PS & TS & GS & PGI \\
\hline PS & 1 & & & \\
\hline TS & $0.546^{* *}$ & 1 & & \\
\hline GS & $0.517^{* *}$ & $0.697^{* *}$ & 1 & \\
\hline PGI & $0.366^{* *}$ & $0.122^{*}$ & $0.248^{* *}$ & 1 \\
\hline
\end{tabular}

TABLE III. RESUlt OF HyPOTHESES TESTS

\begin{tabular}{|l|c|c|c|c|c|c|c|}
\hline \multicolumn{1}{|c|}{ Model } & $\boldsymbol{\beta}$ & $\boldsymbol{T}$ & $\boldsymbol{R}$ & ${\text { Adjust } \boldsymbol{R}^{2}}^{2}$ & $\boldsymbol{F}$ - value & $\boldsymbol{p}$-value & Result \\
\hline$(1) \mathrm{PS} \rightarrow$ PGI & $0.366^{* * *}$ & 7.921 & 0.134 & 0.132 & 62.748 & 0.000 & H1 is supported \\
\hline$(2) \mathrm{GS} \rightarrow$ PGI & $0.248^{* * *}$ & 5.148 & 0.061 & 0.059 & 26.506 & 0.000 & $\mathrm{H} 2$ is supported \\
\hline $\begin{array}{l}\text { (3)TWOM } \\
\rightarrow \text { PGI }\end{array}$ & $0.312^{* * *}$ & 6.610 & 0.097 & 0.095 & 43.693 & 0.000 & H3 is supported \\
\hline$(4)$ TS $\rightarrow$ PGI & $0.122^{*}$ & 2.468 & 0.015 & 0.012 & 6.091 & 0.000 & H4 is supported \\
\hline
\end{tabular}

\section{B. Regression Analysis}

According to the model in "Table III" above, personalized service (PS) has a significant positive impact on personalized group willingness (PGI) $(\beta=0.366, \mathrm{t}=7.921, \mathrm{P}<0.001)$, and the adjusted mode is explained as $13.2 \%, \mathrm{~F}$ value is $62.748(\mathrm{P}$ $=0.000)$, indicating that the more comprehensive the personalized service (PS), the higher the personalized group intention (PGI). Similarly, tourism security (TS), group service (GS) and tourist word-of-mouth (TWOM) have significant positive effects on personalized group intention (PGI). Therefore, $\mathrm{H} 1, \mathrm{H} 2, \mathrm{H} 3$ and $\mathrm{H} 4$ are assumed to be valid. That is to say, when the more comprehensive the personalized service (PS), the higher the tourism safety (TS), the more perfect the group service (GS) and the better the tourists' word-of-mouth (TWOM), the higher the personalized group intention (PGI) of the tourism users.

\section{RECOMMENDATIONS}

According to the research and analysis results of survey data, consumers will consider the four aspects of personalized service, group service, tourist word-of-mouth and tourism safety when choosing personalized group tourism. The more comprehensive the personalized services and group services are, the more intention they are to meet the individual needs of consumers and make them feel satisfied and happy; The better tourist word-of-mouth, the more positive impression they can give consumers, and the stronger their desire for this demand; At the same time, consumers pay more attention to the safety of personalized group tourism. The higher the safety of tourists, the higher is the intention of group tourism. 
prescribed routes, time and activities. Tourists are in a passive position in the whole process of tourism. There is no choice, tourism experience and satisfaction are low, and "group tourism" is rampant, there are many disorderly "group" and "tour" industry chaos. At the same time, the traditional group following model can't meet the needs of the new generation of young people. Therefore, consumers' demand for "group tour" is constantly decreasing. However, if consumers are the leading role in the "group tour", and the members and routes of the group are selected independently to meet the personalized and social interaction needs of consumers, then it is necessary to innovate the mode of group tour, provide comprehensive group service, enhance flexibility and personalization, and meet the needs of consumers; at the same time, standardize the "group tour" and promote the sound development of the "group tour" behavior.

\section{CONCLUSION}

It is found that in order to improve consumers' individual willingness to travel, attention should be paid to the evaluation and word-of-mouth of tourism users, the innovation of personalized customized services, the satisfaction of consumers' spiritual needs and individual choices, the provision of comprehensive services and the safety of users in tourism consumption, which will affect their intention to spend. In order to promote consumers' desire for consumption, tourism market personnel should develop more products and services that meet consumers' needs, create better consumer experience and give tourists a stronger sense of trust.

\section{ACKNOWLEDGMENT}

The authors thank to the support of the Innovation and Entrepreneurship Program of University of Electronic Science and Technology of China, Zhongshan Institute (UESTC), the project number is 2019 CXXL113, and thank to the funding for High-level Talents of UESTC for this study, the project number is $418 \mathrm{YKQN} 16$.

\section{REFERENCES}

[1] Research,"Research Report on China's online development of tourism industry in 2018," iResearch Inc, pp. 1-40, Dec. 2018. Available:

[2] http://report.iresearch.cn/report_pdf.aspx?id=3318,2018.

[3] Wan Xiaoxue, Wang Yichen, Guo Shili, left Jincheng, Wang Lei. The Impact of Personalized Services on the Value of Wine Tourism Experience and Path Study . Modern Marketing (Late Edition), 2018 (08), pp.147-148.

[4] Li Ruirui. Analysis of Changes in the Two Main Players in the Personalized Tourism Market - tourists and Travel Agencies. Special Zone Economy, vol.3, pp. 230-231. Mar. 2006.

[5] Qin Qi, Wang Kai, Zhang Wei, Liu Ying. Service Innovation Research based on the characteristics of "empty nest youth" consumer behavior. Cooperative Economy\& Science, 2019 (01) , pp.136-137.

[6] He Bi.The Disorder of Tourism Market. Orld Market Journal, 2011(1), pp.46-46.

[7] Yang Haidong. The design and realization of the tourism e - commerce system of innovative mode. Intemet fortune - Network World, 2010 (10),pp.174-175.

[8] Yi Xinrui, Yao Guizhao, "Micro Tour: New Ways of Personalized Tourism," Co-Operative Economy \& Science, no.24, pp. 4445.Oct .2017. 
[9] Lu Hanglan. "Internet and Accommodation Community" Personalized Tourism Sharing Mutual Aid Model Development and Prospect Exploration. Travel Overview (Second half of the month), 2018 (08), pp. $15-16$

[10] Armdt J. Role of Product-Related Conversations in the Diffusion of a New Product[J]: Joumal of Marketing Research,1967,4(3), pp.291-295.

[11] Westbrook R A. Product Consumption based Affective Response and Post-purchase Processes[J].Journal of Marketing Researcch,1987, pp.258-270.

[12] Paul M. Herr, Frank R. Kardes and John Kim, "Effects of Word-ofMouth and Product-Attribute Information on Persuasion: An Accessibility-Diagnosticity Perspective,"Journal of Consumer Research, Great Clarendon St.Oxford OX2 6DP, UK: Oxford University Press, vol. 17, no. 4 , pp. 454-462.Mar. 1991 .

[13] Wu Chuanbiao, Wan Shaojuan. Tourist Experience, The Quality of The Host Relationship and Post-Tour Word-of-Mouth Relationship and Management Enlightenment--Based on the Empirical Analysis of Tourists to Dalian, Tourism Research, 2014, (2) , pp.38-43, 50.

[14] Song Haoyuan, Wei Mengying, Zhang Mingyan, Huang Mengting, Fang Zhou. An Empirical Study on China's Online Tourism Demand in mode 020. E-Business Journal, no.7,pp.18-20,89.Jul.2015.

[15] Zhuang Zehui, Yuan Mingxia, Fan Weisheng, Zheng Guokai, "Modern e-commerce Personalized Tourism Market Analysis,"Co-Ooperative Economy\& Science, vol.607, no.8, pp. 84-86. Jan.2019.

[16] Yang Qinqin, Xie Chaowu. Tourist micro - the interaction effect of macro security perception and willingness to travel - based on a case study of the Paris attacks. Journal of Tourism, 2018, 33 (5) , pp.68-78.

[17] MA Qiuling, LONG Chunfeng. A Four-dimentional Analysis of Customized Tourism Service Innovation. Journal of Sichuan Institute of Tourism University, no.137, pp. 53-57. Apr. 2018.

[18] Li Qian, Xu Wei, Jiang Hongxun. Personalized Recommendation for Traveling Planning Based on Online Word-of-mouth. Management Review, Vol. 28, no.6, pp.113-118, Jun. 2016.

[19] Zhang Fuguo, Zeng Buxin, Song Xiangyu .Research Status of Overseas Personalized Tourism Recommendation. Science Mosaic, no.9, pp. 2632. 2017.

[20] Li Kai, Wang Xiaowen. A Mechanism Study on the Impact of Privacy Concern on the Personalized Service of Travel Websites.Tourism Tribune. Vol. 26, no.6, pp.80-86.Jan.2011. 